\title{
Direct conversion of alcohols to long-chain hydrocarbons via tandem dehydrogenation-decarbonylative olefination
}

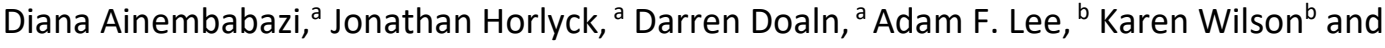 \\ Adelina M. Voutchkova-Kostal ${ }^{\mathrm{a}^{*}}$ \\ a Chemistry Department, the George Washington University, $80022^{\text {nd }}$ St NW, Washington D.C. 20910; ${ }^{b}$ \\ School of Science, RMIT University, Melbourne, VIC, 3001, Australia; Email: avoutchkova@gwu.edu;
}

Design of active and selective supported catalysts is critical for developing new tandem processes for upgrading biomassderived alcohols. Hydrogen-free upgrading alcohols to liquid hydrocarbons is desirable for producing drop-in fuel substitutes, but direct and atom-economical processes are yet to be reported. Here we report a novel alcohol upgrading and deoxygenation cascade that meets these criteria. This hydrogen-free cascade is catalyzed by multifunctional $\mathrm{Pd}$ catalysts, whose supports feature a range of acid-base properties: primarily basic $\mathrm{MgO}$, acidic $\mathrm{Al}_{2} \mathrm{O}_{3}$ and $\mathrm{Mg}-\mathrm{Al}$ hydrotalcite $(\mathrm{HT})$ with a combination of Lewis acidic and basic sites. The impact of support selection on selectivity offers insights into the design principles for next-generation catalysts for this process and related transformations.

The ability to produce liquid hydrocarbon fuels from renewable biomass is a highly attractive strategy for producing drop-in fuel substitutes with high energy density ${ }^{1}$ and for existing petrochemical processes. As renewable sources of alcohols become increasingly abundant, ${ }^{2}$ interest in their catalytic conversion to energy-dense hydrocarbons is also growing, ${ }^{3}$ but is yet to be realized in an efficient manner. Practical processes for such transformations should be energy-efficient, use low-cost, robust, heterogeneous catalysts, and be tolerant to aqueous, dilute alcohol feedstreams, such as those often derived from fermentation processes. Achieving these objectives requires the design of active and selective supported catalysts tailored for new tandem processes based on the upgrading of biomass-derived alcohols. Current approaches to upgrading alcohols primarily rely on the Guerbet condensation, wherein alcohols are coupled to produce longer-chain, branched primary alcohols through a sequence of dehydrogenation, aldol condensation and hydrogenation reactions (Scheme 1 , Reaction $A$ ). ${ }^{4-15}$

The Guerbet reaction can be catalysed by supported noble metal catalysts, metal oxides and mixed metal oxides (MMOs). The latter may be derived by calcination of layered double hydroxides (LDHs), and their selectivity tuned through altering the composition and morphology.4, 5, 9-11, 14, 15 However, to our knowledge there are no reports of alcohol coupling processes able to upgrade primary alcohols to alkanes or alkenes (Scheme 1, Reaction B), as described here. Effecting the requisite tandem transformations in a one-pot reaction (to minimize reactor complexity and cost) necessitates multifunctional catalysts possessing catalytic sites effective for dehydrogenation, aldol condensation and decarbonylation. Optimizing the formulation and operation of multifunctional catalysts is generally challenging, since it hinges on controlling the activity and selectivity of several interdependent steps. In turn, this requires control over the size, location and structure of catalytically active species, and mechanistic insight into corresponding structure-activity relationships, including the role of supports. ${ }^{16}$ Efforts by our group and others to develop Pd catalysts ion tunable supports for organic synthesis and biomass valorisation have identified strong interactions with support matrices that regulate metal speciation and resulting reactivity. ${ }^{17-23,24}$

$\mathrm{MgO}$ and $\mathrm{Al}_{2} \mathrm{O}_{3}$ supported metal catalysts are well-known to present different acid-base properties: $:^{25-28}$ Saad et al. reported Pt-supported $\mathrm{MgO}$ displays strong basicity, whereas Pt- $\mathrm{Al}_{2} \mathrm{O}_{3}$ displays strong acidity. ${ }^{24}$ Similar observations were made by Groppo et al. for Pd analogues. ${ }^{29}$ Hydrotalcites (HTs) are a sub-set of $\mathrm{LDHs}$ with general formula $\left[\mathrm{M}^{2+}{ }_{1-}\right.$ $\left.{ }_{x} \mathrm{M}^{3+}{ }_{x}(\mathrm{OH})_{2}\right]^{\mathrm{x}+}\left(\mathrm{A}^{\mathrm{n}-}\right)_{\mathrm{x} / \mathrm{n}} \cdot \mathrm{mH}_{2} \mathrm{O}$, where $\mathrm{M}^{2+}$ and $\mathrm{M}^{3+}$ are $\mathrm{Mg}^{2+}$ and $\mathrm{Al}^{3+}$ or compatible alkali earth and transition metal cations. ${ }^{30}$ Although LDH materials similar to the present HT exhibit basic properties approaching those of $\mathrm{MgO}^{31}$ the tunable nature of such materials means that both $\mathrm{O}^{2-}$ and $\mathrm{Al}^{3+}$ respective Lewis base and acid centres are accessible. ${ }^{32,33}$

Scheme 1: Upgrading of primary alcohols to longer chain alcohols (A) and hydrocarbons *B).

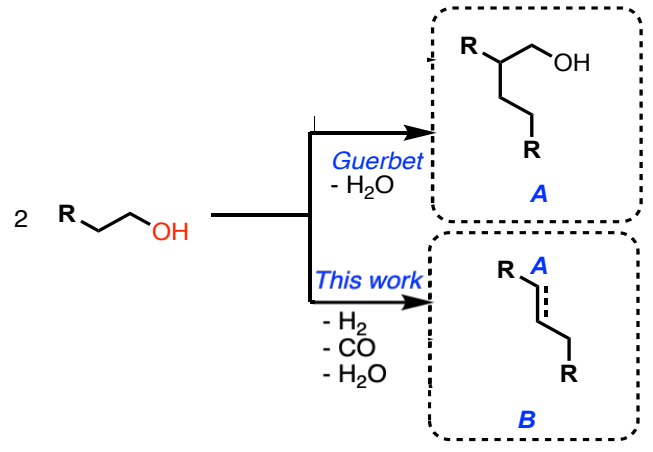


The unique reactivity of palladium (Pd) doped-LDH (or hydrotalcite, HT) catalysts includes decarbonylation of aldehydes, ${ }^{19}$ aldol condensations ${ }^{17}$ and acceptorless alcohol and amine dehydrogenation: ${ }^{18,} 34$ elementary steps in our proposed alcohol upgrading route. Recently, we reported highly active $\mathrm{Pd}-\mathrm{HT}$ catalysts for the atom-economical olefination of carbonyls via aldol-decarbonylative coupling of aldehydes (with aldehyde serving as nucleophilic enol/enolate), producing only $\mathrm{CO}$ and $\mathrm{H}_{2} \mathrm{O}$ by-products. ${ }^{17} \mathrm{We}$ postulated that similar catalysts could be applied to alcohols to selectively afford long-chain alkanes and alkenes via acceptorless dehydrogenation and decarbonylative coupling. The significantly higher barrier for decarbonylation than aldol condensation should control the reaction sequence such that initial alcohol dehydrogenation would afford the aldehyde which would then undergo stepwise aldol condensation and decarbonylation to the alkene.

Here we demonstrate the feasibility of hydrogen-free alcohol upgrading and deoxygenation over multifunctional Pd catalysts, featuring supports possessing different acid-base properties: ${ }^{35,36} \mathrm{MgO}$, with primarily basic character; a HT with Lewis acidic and basic sites; and $\mathrm{Al}_{2} \mathrm{O}_{3}$, with primarily acidic character.

Physicochemical properties of the three catalysts were investigated by ICP-OES, TEM, XPS and PXRD (see Catalyst Characterization in ESI). XPS revealed significant differences in Pd surface speciation for each support (Figure S1). All catalysts comprise $\mathrm{Pd}^{2+}$ as the major species in addition to $\mathrm{Pd}^{0}$, with $\mathrm{Pd}-\mathrm{MgO}$ and $\mathrm{Pd}-\mathrm{Al}_{2} \mathrm{O}_{3}$ also exhibiting a low level of $\mathrm{Pd}^{4+}$. The $\mathrm{Pd}^{2+}$ surface concentration was highest for $\mathrm{Pd}-\mathrm{Al}_{2} \mathrm{O}_{3}$, whereas $\mathrm{Pd}-\mathrm{HT}$ shows the greatest $\mathrm{Pd}(0)$ concentration, suggesting that the support acid-base properties impact $\mathrm{Pd}$ speciation. Corresponding TEM images (Figure 1) reveal oxide agglomerates decorated with palladium nanoparticles typical of wet impregnation syntheses. ${ }^{37,} 38$ Nanoparticles (NPs) dispersed over $\mathrm{Al}_{2} \mathrm{O}_{3}$ and $\mathrm{HT}$ supports exhibited the size and shape uniformity, with mean diameters of $3.7 \mathrm{~nm}$ and $2.4 \mathrm{~nm}$ respectively. Nanoparticles on $\mathrm{Pd}-\mathrm{MgO}$ were not as readily identifiable in either bright field nor dark field TEM; nevertheless, those identified had a mean diameter of 3.5 $\mathrm{nm}$, but with broader size distribution than those of the former two.

The Pd catalysts were subsequently tested for alcohol coupling using heptanol (1) as the substrate at $180{ }^{\circ} \mathrm{C}$. The proposed mechanism for the process is shown in Scheme 2. Initial dehydrogenation produces aldehyde $\mathbf{6}$, which can either undergo ketal hydrogenolysis ${ }^{39}$ to form 2, alcohol addition and dehydrogenation to form ester $\mathbf{3}$, or aldol condensation to form 7. Double transfer hydrogenation (TH) tof $\mathbf{7}$ (with hydrogen adatoms from alcohol dehydrogenation) forms the Guerbet alcohol (5); alternatively, decarbonylation of $\mathbf{7}$ forms alkene $\mathbf{8}$, which can be hydrogenated to alkane $\boldsymbol{9}$ over Pd metal. As reported by Li et al. ${ }^{13}$ and Zhang et al., ${ }^{8}$ the selectivity for Guerbet alcohol $\mathbf{5}$ is promoted by co-operative acid and base catalysis, as possible for our Pd-HT.
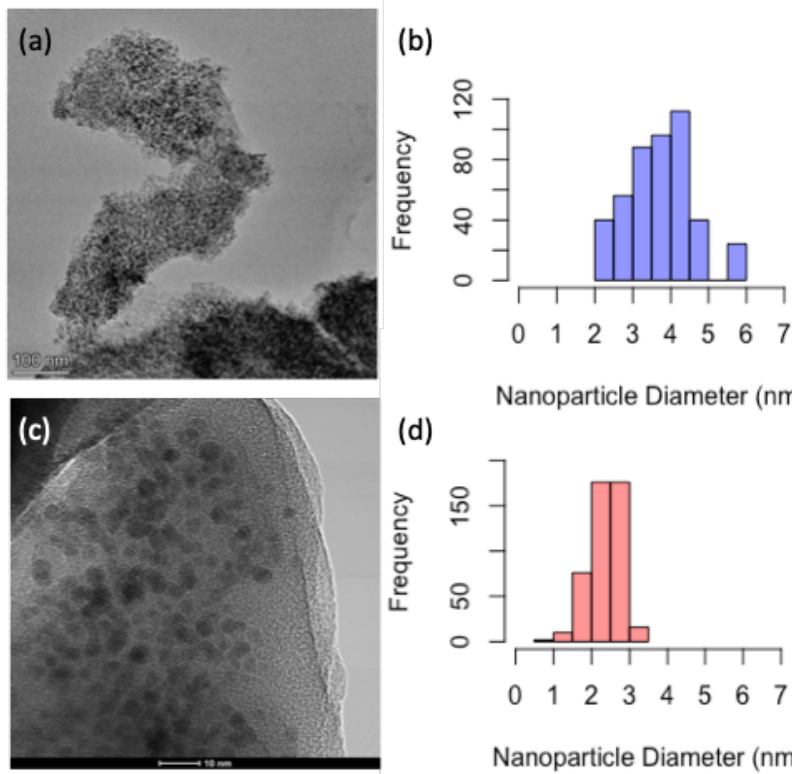

(d)

Nanoparticle Diameter $(\mathrm{nm})$

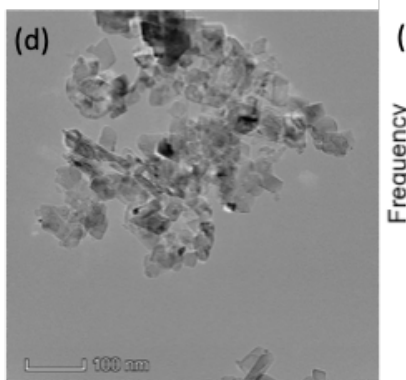

(e)
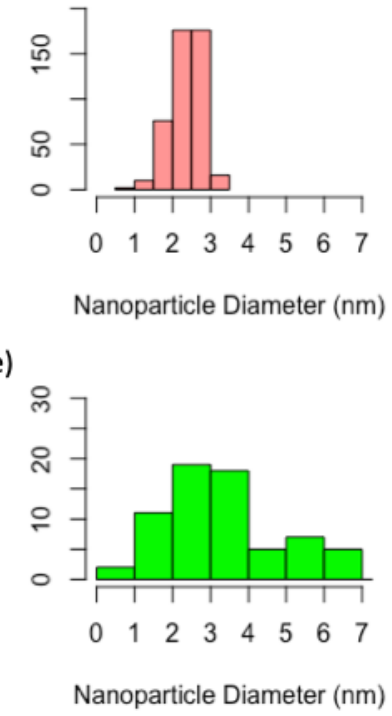

Figure 1. Bright field TEM images and corresponding Pd particle size distributions for $(\mathrm{a}, \mathrm{b}) \mathrm{Pd}-\mathrm{Al}_{2} \mathrm{O}_{3},(\mathrm{c}, \mathrm{d}) \mathrm{Pd}-\mathrm{HT}$, and $(\mathrm{e}, \mathrm{f}) \mathrm{Pd}-$ MgO.

Control reactions with $\mathrm{Pd}$-free $\mathrm{MgO}, \mathrm{HT}$ and $\mathrm{Al}_{2} \mathrm{O}_{3}$ supports showed no heptanol conversion. $\mathrm{Pd}_{-} \mathrm{Al}_{2} \mathrm{O}_{3}$ afforded $>90 \%$ alcohol conversion in $48 \mathrm{~h}$, with diheptyl ether as the major product (2, 97\% selectivity). Only trace heptyl heptanoate (3) was observed and no alkene products (Figure 2). This high ether selectivity is attributed to Pd-catalysed ketal hydrogenolysis, ${ }^{41}$ proceeding via heptanal, or acid-catalysed alcohol dehydration over strong Lewis acidic $\mathrm{Pd}^{+}$sites. $\mathrm{Pd}$ participation is inferred from the fact that $\mathrm{Al}_{2} \mathrm{O}_{3}$ affords no conversion with neither hepatanol, nor heptanal and heptanol.

Scheme 2. Proposed mechanism for the conversion of alcohols to alkenes (red), alkanes (maroon) and other by-products.

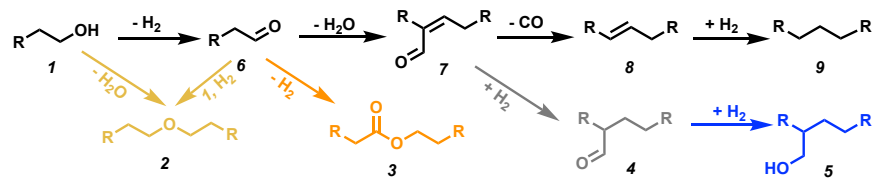




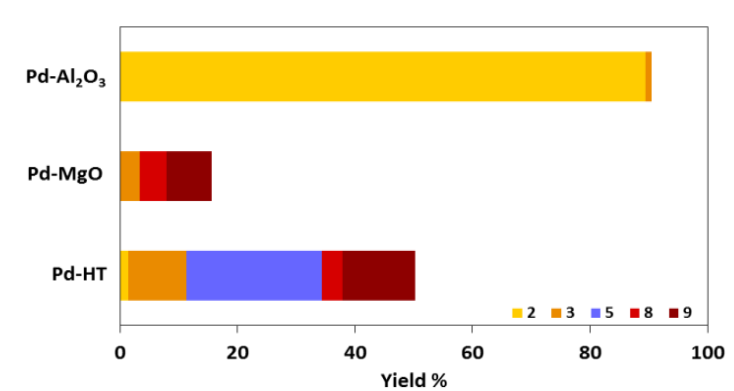

Figure 2. Product yield and selectivity for $n$-heptanol coupling over supported Pd catalysts. Conditions: $0.2 \mathrm{~mol} \% \mathrm{Pd}, 180^{\circ} \mathrm{C}$, $48 \mathrm{~h}$, in air.

A comparable reaction with $\mathrm{Pd}-\mathrm{HT}$ affords negligible quantity of the ether (3); instead, we observe near complete selectivity for products arising from initial alcohol dehydrogenation (Scheme 2): $46 \%$ selectivity for Guerbet alcohol (5), 7\% for 6-E-tridecene (8), 22\% for tridecane (9) and $22 \%$ ester 3 (with $50 \%$ alcohol conversion). Pd-HT is thus significantly more efficient at facilitating the initial alcohol dehydrogenation than $\mathrm{Pd}-\mathrm{Al}_{2} \mathrm{O}_{3}$, likely due to the higher concentration of $\mathrm{Pd}$ metal sites. ${ }^{13}$ Product selectivity is dictated by the subsequent fate of heptanal: reaction with the parent alcohol and dehydrogenation forms the ester 3, whereas aldol condensation affords (7) which in turn unlocks access to saturated oxygenates $(4,5)$ or alkenes/alkanes $\mathbf{8 / 9}$. The molar ratio of ester 3 to the observed aldol reaction products $(5,8$ and 9$)$ of 1:3.6 evidences that the strong basic sites in the HT support promote aldol condensation..$^{15}$ In contrast, the lack of basic sites and weak acidic sites on $\mathrm{Al}_{2} \mathrm{O}_{3}$ promote ether formation (3) by either dehydration or ketal hydrogenolysis, as previously reported by Marecot et al. ${ }^{41}$

Since downstream hydrogenation is dependent on the rate of the upstream dehydrogenation, ${ }^{7}$ the selectivity for 5 versus hydrocarbons ( 8 and 9$),(\sim 2: 1$ for Pd-HT) reflects the relative rates of re-hydrogenation versus decarbonylation of the reactively-formed aldol product 7 . High selectivity to hydrocarbons requires faster decarbonylation, which in turn will depend on the Pd speciation. ${ }^{19,40}$

Compared to the other catalysts, Pd-MgO was significantly less active for heptanol conversion (16\%), but exhibited the highest selectivity for hydrocarbons 8 (29\%) and 9 (50\%), alongside ester 3 . These observations suggest that $\mathrm{Pd}-\mathrm{MgO}$ possesses few or weak Lewis acid sites and limited Pd metal sites, accounting for slow dehydrogenation and no dehydration, and favoring decarbonylation over rehydrogenation of the aldol condensate $\mathbf{7}$. We anticipate that optimizing the Pd loading and particle size (both strong influencers of palladium speciation $)^{41}$ could significantly increase dehydrogenation activity, and hence heptanol conversion and the hydrocarbon yield.

Further mechanistic insight was obtained by investigating the three catalysts for the decarbonylative coupling of heptanal via stepwise aldol condensation and decarbonylation (Figure
S3). All three catalysts showed high activity and selectivity for the desired alkene 8 in $8 \mathrm{~h}$ at $180{ }^{\circ} \mathrm{C}$, with yields of 8 of $97 \%$ $\left(\mathrm{Pd}-\mathrm{Al}_{2} \mathrm{O}_{3}\right), 92 \%(\mathrm{Pd}-\mathrm{MgO})$ and $85 \%(\mathrm{Pd}-\mathrm{HT})$, the latter reflecting incomplete decarbonylation of the aldol condensate 7. The lower olefin yield afforded by Pd-HT relative to $\mathrm{Pd}-\mathrm{MgO}$ suggests the former is a less efficient decarbonylation catalyst of the two. This is consistent with the selectivity observed for the alcohol reaction: Pd-HT affords $\sim 3: 2$ ratio of Guerbet alcohol (5) to hydrocarbons 8 and 9, while $\mathrm{Pd}-\mathrm{MgO}$ affords no alcohol 5. Thus, driving selectivity for the hydrocarbons requires optimizing catalytic efficiency of decarbonylation. The experiment also suggests that the rate-determining step in hydrocarbon formation catalysed by $\mathrm{Pd}-\mathrm{MgO}$ is dehydrogenation of the parent alcohol.

To rationalize the ratio of alkene 8 versus alkane 9 , and thus the ability of the catalyst to facilitate transfer hydrogenation (TH) of alkenes to alkanes, we compared the efficiency of the three catalysts for the TH of 6-E-tridecene ( 8 in Scheme 2 ) using 2-propanol as hydrogen donor (Scheme 3). Pd-MgO afforded $\sim 4$-fold lower yield of alkane than Pd-HT (15\% vs $62 \%)$, consistent with the lower fraction of $9: 8$ afforded by $\mathrm{Pd}-\mathrm{MgO}$ in the heptanol reaction (1:1.7 for and 1:3.4 with Pd$\mathrm{MgO}$ and $\mathrm{Pd}-\mathrm{HT}$ respectively, Figure 2). This trend is also consistent with the faster heptanol conversion observed for $\mathrm{Pd}-\mathrm{HT}$ compared to $\mathrm{Pd}-\mathrm{MgO}$. Interestingly, $\mathrm{Pd}-\mathrm{Al}_{2} \mathrm{O}_{3}$ affords $51 \%$ yield of 9 , suggesting it too is an efficient TH catalyst. However, as previously discussed, $\mathrm{Pd}-\mathrm{Al}_{2} \mathrm{O}_{3}$ favors formation of ether 2, and hence does not form alkene (Figure 2). In a similar experiment with aldol product 7 , we find $\mathrm{Pd}-\mathrm{HT}$ is $\sim 2$ fold more active than Pd-MgO for formation of alcohol 5. Thus, the selectivity of Pd-MgO for $\mathbf{8}$ and $\boldsymbol{9}$ over $\mathbf{5}$ is the result of its faster decarbonylation and slower TH relative to that of $\mathrm{Pd}-\mathrm{HT}$.

Scheme 3. Transfer hydrogenation of tridec-6-ene using 2-propanol.

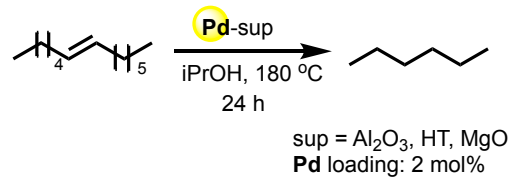

\section{Conclusion}

Pd supported on both basic and acidic supports (MgO and hydrotalcite, HT) are promising heterogeneous catalysts for a novel alcohol upgrading route to long-chain hydrocarbons proceeding via tandem dehydrogenation, aldol condensation and decarbonylation. Initial results with heptanol show that the support acid-base properties influence Pd speciation, and catalytic activity for each reaction steps. Pd-MgO exhibits highest selectivity to alkene and alkane products, but lowest conversion, whereas Pd-HT offers high conversion but lower selectivity for hydrocarbons, as it is less active for decarbonylation. $\mathrm{Pd}-\mathrm{Al}_{2} \mathrm{O}_{3}$ affords only ethers, likely due to faster ketal hydrogenolysis than aldol condensation. Optimum hydrocarbon formation requires synergy between 
Pd metal and support acidic/basic sites, as well as optimization of the four sequential catalytic steps required for the transformation. Further investigations into the design of more active and selective multifunctional catalysts for this attractive alcohol coupling pathway are underway.

\section{Acknowledgements}

AV-K thanks NSF CBET for support of this work (award 1805080) and the GWU Material Institute and Surface Analysis Center at University of Maryland for use of instrumentation in catalyst characterization.

\section{References}

1. G. W. Huber, J. N. Chheda, C. J. Barrett and J. A. Dumesic, Science, 2005, 308, 1446-1450.

2. D. Sun, S. Sato, W. Ueda, A. Primo, H. Garcia and A. Corma, Green Chemistry, 2016, 18, 2579-2597.

3.2011

4. J. A. Barrett, Z. R. Jones, C. Stickelmaier, N. Schopp and P. C. Ford, ACS Sustainable Chemistry \& Engineering, 2018, 6, 15119-15126.

5. J. J. Bravo-Suárez, B. Subramaniam and R. V. Chaudhari, Applied Catalysis A: General, 2013, 455, 234-246.

6. Z. Sun, A. Couto Vasconcelos, G. Bottari, M. C. A. Stuart, G. Bonura, C. Cannilla, F. Frusteri and K. Barta, ACS Sustainable Chemistry \& Engineering, 2017, 5, 1738-1746.

7. M. León, E. Díaz and S. Ordóñez, Catalysis Today, 2011, 164, 436-442.

8. J. Zhang, K. Shi, Z. An, Y. Zhu, X. Shu, H. Song, X. Xiang and J. He, Industrial \& Engineering Chemistry Research, 2020, 59, 3342-3350.

9. O. V. Larina, K. V. Valihura, P. I. Kyriienko, N. V. Vlasenko, D. Y. Balakin, I. Khalakhan, T. Čendak, S. O. Soloviev and S. M. Orlyk, Applied Catalysis A: General, 2019, 588, 117265.

10. M. Rechi Siqueira, O. Micali Perrone, G. Metzker, D. C. de Oliveira Lisboa, J. C. Thoméo and M. Boscolo, Molecular Catalysis, 2019, 476, 110516.

11. P. Benito, A. Vaccari, C. Antonetti, D. Licursi, N. Schiarioli, E. Rodriguez-Castellón and A. M. Raspolli Galletti, Journal of Cleaner Production, 2019, 209, 1614-1623.

12. S. Marx and B. Ndaba, Biofuels, 2019, 1-8.

13. X. N. Li, S. S. Peng, L. N. Feng, S. Q. Lu, L. J. Ma and M. B. Yue, Microporous and Mesoporous Materials, 2018, 261, 44-50.

14. M. León, E. Díaz, A. Vega, S. Ordóñez and A. Auroux, Applied Catalysis B: Environmental, 2011, 102, 590-599.

15. I.-C. Marcu, D. Tichit, F. Fajula and N. Tanchoux, Catalysis Today, 2009, 147, 231-238.

16. M. Crespo-Quesada, A. Yarulin, M. S. Jin, Y. N. Xia and L. Kiwi-Minsker, Journal of the American Chemical Society, 2011, 133, 12787-12794.

17. D. Ainembabazi, C. Reid, A. Chen, N. An, J. Kostal and A. Voutchkova-Kostal, Journal of the American Chemical Society, 2020, 142, 696-699.
18. D. Ainembabazi, N. An, J. C. Manayil, K. Wilson, A. F. Lee and A. M. Voutchkova-Kostal, ACS Catalysis, 2019, 9, 1055-1065.

19. N. An, D. Ainembabazi, C. Reid, K. Samudrala, K. Wilson, A. F. Lee and A. Voutchkova-Kostal, ChemSusChem, 2020, 13, 312-320.

20. M. A. Stranick, M. Houalla and D. M. Hercules, Journal of Catalysis, 1990, 125, 214-226.

21. A. Davantès, C. Schlaup, X. Carrier, M. Rivallan and G. Lefèvre, The Journal of Physical Chemistry C, 2017, 121, 21461-21471.

22. O. Borg, P. Dietzel, A. Spjelkavik, E. Tveten, J. Walmsley, S. Diplas, S. Eri, A. Holmen and E. Rytter, Journal of Catalysis, 2008, 259, 161-164.

23. B. N. Shelimov, J. F. Lambert, M. Che and B. Didillon, Journal of Molecular Catalysis A: Chemical, 2000, 158, 9199.

24. F. Saad, J. D. Comparot, R. Brahmi, M. Bensitel and L. Pirault-Roy, Applied Catalysis A: General, 2017, 544, 1-9.

25. B.-Q. Xu, T. Yamaguchi and K. Tanabe, Chemistry Letters, 1988, 17, 1663-1666.

26. H. P. Aytam, V. Akula, K. Janmanchi, S. R. R. Kamaraju, K. R. Panja, K. Gurram and J. W. Niemantsverdriet, The Journal of Physical Chemistry B, 2002, 106, 1024-1031.

27. W. Gac, Applied Surface Science, 2011, 257, 2875-2880.

28. C. Poupin, R. Maache, L. Pirault-Roy, R. Brahmi and C. T. Williams, Applied Catalysis A: General, 2014, 475, 363370.

29. E. Groppo, S. Bertarione, F. Rotunno, G. Agostini, D. Scarano, R. Pellegrini, G. Leofanti, A. Zecchina and C. Lamberti, The Journal of Physical Chemistry C, 2007, 111, 7021-7028.

30. F. Cavani, F. Trifiro and A. Vaccari, Catal Today, 1991, 11, 173-301.

31. Y. He, P. Yang, J. Fan, Y. Liu, Y. Du, J. Feng, F. Fan and D. Li, RSC Advances, 2015, 5, 74907-74915.

32. M. G. Álvarez, R. J. Chimentão, F. Figueras and F. Medina, Applied Clay Science, 2012, 58, 16-24.

33. O. D. Pavel, D. Tichit and I.-C. Marcu, Applied Clay Science, 2012, 61, 52-58.

34. J. Bain, P. Cho and A. Voutchkova-Kostal, Green Chemistry, 2015, 17, 2271-2280.

35. G. J. S. Dawes, E. L. Scott, J. Le Nôtre, J. P. M. Sanders and J. H. Bitter, Green Chemistry, 2015, 17, 3231-3250.

36. J. A. Lopez-Ruiz and R. J. Davis, Green Chemistry, 2014, 16, 683-694.

37. Y. He, J. Fan, J. Feng, C. Luo, P. Yang and D. Li, Journal of Catalysis, 2015, 331, 118-127.

38. S. R. Akuri, C. Dhoke, K. Rakesh, S. Hegde, S. A. Nair, R. Deshpande and P. Manikandan, Catalysis Letters, 2017, 147, 1285-1293.

39. V. Bethmont, C. Montassier and P. Marecot, J. Mol. Cat. A, 2000, 152, 133-140.

40. V. Vorotnikov, G. Mpourmpakis and D. G. Vlachos, ACS Catalysis, 2012, 2, 2496-2504.

41. C. M. A. Parlett, D. W. Bruce, N. S. Hondow, A. F. Lee and K. Wilson, ACS Catalysis, 2011, 1, 636-640. 